\title{
CPT1A Supports Castration-Resistant Prostate Cancer in Androgen-Deprived Conditions
}

\author{
Molishree Joshi ${ }^{1}$, Gergana E. Stoykova ${ }^{2}$, Maren Salzmann-Sullivan ${ }^{2}$, Monika Dzieciatkowska ${ }^{3}$, \\ Lauren N. Liebman ${ }^{2}$, Gagan Deep ${ }^{4}$ and Isabel R. Schlaepfer ${ }^{2, *(D)}$ \\ 1 Department of Pharmacology, University of Colorado Anschutz Medical Center, Aurora, CO 80045, USA; \\ Molishree.Joshi@cuanschutz.edu \\ 2 Division of Medical Oncology, University of Colorado Anschutz Medical Center. Aurora, CO 80045, USA; \\ gergana.stoykova@ucdenver.edu (G.E.S.); maren.salzmann-sullivan@cuanschutz.edu (M.S.-S.); \\ lliebman@umich.edu (L.N.L.) \\ 3 Department of Biochemistry, University of Colorado Anschutz Medical Center, Aurora, CO 80045, USA; \\ monika.dzieciatkowska@cuanschutz.edu \\ 4 Department of Cancer Biology, Wake Forest Baptist Medical Center, Winston-Salem, NC 27157, USA; \\ gdeep@wakehealth.edu \\ * Correspondence: isabel.schlaepfer@cuanschutz.edu; Tel.: +1-303-7244430
}

Received: 19 August 2019; Accepted: 18 September 2019; Published: 20 September 2019

\begin{abstract}
Prostate cancer (PCa) is the most common cancer in men, and the global burden of the disease is rising. The majority of PCa deaths are due to metastasis that are highly resistant to current hormonal treatments; this state is called castration-resistant prostate cancer (CRPC). In this study, we focused on the role of the lipid catabolism enzyme CPT1A in supporting CRPC growth in an androgen-dependent manner. We found that androgen withdrawal promoted the growth of CPT1A over-expressing (OE) tumors while it decreased the growth of CPT1A under-expressing (KD) tumors, increasing their sensitivity to enzalutamide. Mechanistically, we found that CPT1A-OE cells burned more lipid and showed increased histone acetylation changes that were partially reversed with a p300 specific inhibitor. Conversely, CPT1A-KD cells showed less histone acetylation when grown in androgen-deprived conditions. Our results suggest that CPT1A supports CRPC by supplying acetyl groups for histone acetylation, promoting growth and antiandrogen resistance.
\end{abstract}

Keywords: CPT1A; prostate cancer; androgen receptor; histone acetylation; enzalutamide; dihydrotestosterone

\section{Introduction}

Prostate cancer (PCa) is the most common cancer in men [1], and the global burden of the disease is rising. In the United States, PCa causes nearly 30,000 deaths and 230,000 new cases yearly, making the search for new therapeutic approaches imperative. The majority of PCa deaths are due to metastasis that are highly resistant to current hormonal treatments [2,3].

Androgen-deprivation treatment (ADT) is currently the standard treatment for PCa that is localized or metastatic. Despite initial benefits of the androgen removal, some patient's progress to an advanced disease state called castration-resistant prostate cancer (CRPC). This is the lethal form of the disease with limited treatment options, and it is still dependent on the androgen and androgen receptor (AR) axis. In fact, a salient characteristic of CRPC is reactivation of AR signaling. Extensive research has shown that most AR-regulated genes (androgen-response hallmark genes) are re-expressed in CRPC, and several mechanisms by which AR activity is preserved have been reported [4-6]. Recently, improved AR antagonists, also called anti-androgens, have shown to extend survival [7,8], but full remissions are rare. The main problem with using these potent AR inhibitors is the emergence of 
resistance, driven by mechanisms such as AR amplification, mutations, and alternative spliced variants, among others [9]. Another aspect of ADT is the profound changes to body weight and the lipid profile, with increases in triglycerides, cholesterol, and lipoproteins $[10,11]$. The ability of CRPC to use this increased circulating lipid for growth and anti-androgen resistance is still unknown.

The role of lipids in PCa has been studied for the last few decades [12-14], and a connection between lipid metabolism and CRPC is starting to emerge $[15,16]$. However, the way CRPC uses lipid and its dependency on beta-oxidation is still unexplored. A key player in lipid oxidation is the rate-limiting enzyme carnitine palmitoyltransferase 1 (CPT1), which works by transferring long-chain fatty acids into the mitochondria for oxidation [17]. In PCa, inhibition of CPT1A (the liver isoform of CPT1) reduces viability of LNCaP and VCaP cells and tumors [18], and increases PCa sensitivity to the anti-androgen enzalutamide $[19,20]$. Other studies have also shown that lipid oxidation is important for cancer survival [21], resistance to aniokis [22], and activation of oncogenic pathways [23]. However, it is unknown how lipid burning in the mitochondria is associated with AR in the nucleus and how this relationship can promote CRPC.

Besides being a limiting step for fat oxidation and ATP generation, $C P T 1 A$ is also necessary for generating metabolic intermediates to synthesize macromolecules like lipids and nucleic acids, which are both essential for cancer growth. A recent study in endothelial cell sprouting has shown that CPT1A is needed to generate acetyl-coenzyme A (acetyl-CoA), which enters the TCA cycle and generates metabolic intermediates needed for de novo nucleotide synthesis, leading to DNA replication and proliferation [24]. Another study using immortalized hepatocytes has shown that fat oxidation is a major carbon source for histone acetylation, modulating lipid metabolism and reprogramming gene expression [25]. More recently, CPT1A has been implicated in lymphangiogenesis, promoting the generation of acetyl-CoA and acetylation capacity of the histone acetyl transferase p300 to acetylate histones at angiogenic gene promoters [26]. Thus, recent studies point to CPT1A as a lipid metabolic enzyme with the potential to modify macromolecule synthesis as well as gene expression.

Since the relevance of increased CPT1A expression in advanced PCa is emerging [19], in this study, we investigated the role of $C P T 1 A$ in castration-resistant cell and tumor models. We used genetic models of CPT1A knockdown (KD) and overexpression (OE) and challenged them with androgens or enzalutamide. Particularly, we focused on the association between CPT1A in the mitochondria and the androgen response in the nucleus, with the hope of elucidating the nature of their relationship and the possibility of exploiting it for better CRPC therapies.

\section{Materials and Methods}

\subsection{Cell Lines and Reagents}

LNCaP-C4-2 cells were purchased from the University of Texas MD Anderson Cancer Center (Houston, TX, USA). Cell lines (22Rv1) were obtained from the University of Colorado Cancer Center (UCCC) Tissue Culture Shared Resource (2014) (Aurora, CO, USA) and were authenticated by Single Tandem Repeat analysis. Cells were passaged in RPMI media containing 10\% serum supplemented with amino acids and Insulin (Thermo Fisher, Waltham, MA, USA). MDV3100 or enzalutamide (Selleckchem, Houston, TX, USA) was dissolved as a $20 \mathrm{mM}$ stock in DMSO. Stocks were kept at $-20^{\circ} \mathrm{C}$ until ready to use. Fatty acids were purchased from Sigma (St. Louis, MO, USA), resuspended in ethanol for a stock solution of $10 \mathrm{mM}$, and stored at $-80{ }^{\circ} \mathrm{C}$. For cell use, fatty acids were first conjugated to $10 \%$ albumin, and then applied to cell media at the indicated concentrations.

\subsection{Clonogenic Growth, Migration, and Growth in Suspension Assays}

Clonogenic growth assays were done by plating cells in 12-well plates (Light Labs Colorado, Aurora, CO, USA) in media supplemented with fetal bovine serum (FBS) or charcoal-stripped serum (CSS) and the indicated drug doses. Crystal violet stains were analyzed with ImageJ software (https://imagej.nih.gov/ij/), as previously described [19]. Migration was done using the Incucyte ${ }^{\circledR}$ 
Live Cell Analysis System (Sartorius, Ann Arbor, MI, USA), and analysis performed according to manufacturer's instructions. Cell growth in suspension was done by growing the cells in ultra-low cell attachment plates (Sigma Aldrich, St. Louis, MO, USA) for 2 weeks, and imaging the spheres with an Olympus IX83 scope (Tokyo, Japan) and DP74 camera (Tokyo, Japan), followed by ImageJ analysis.

\subsection{Seahorse Metabolic Flux Analysis}

Mitochondrial respiration was done at the molecular and cellular analytical core at the University of Colorado, using a Seahorse XFe96 Analyzer with 96-well plates (Santa Clara, CA, USA). We measured oxygen consumption rate (OCR) using the XF Cell Mito Stress test, which provides a standard method to assess mitochondrial function in live cells. This test uses Oligomycin, FCCP ((4-(trifluoromethoxy) phenyl) carbonohydrazonoyl dicyanide) and a mix of rotenone and antimycin A to modulate the electron transport chain. We plated 40,000 cells/well and treated them overnight with no serum, and supplemented the next day with $50 \mathrm{uM}$ fatty acids and albumin two hours before the assay. Assay media contained no glucose nor bicarbonate, and the $\mathrm{pH}$ was adjusted to 7.4. As a control, we also supplemented the cells with albumin by itself, free of fatty acids. Analysis was performed with Seahorse Wave software (Agilent, Santa Clara, CA, USA).

\subsection{Immunofluorescence and Microscopy}

LNCaP-C4-2 cells were grown in $22 \mathrm{~mm}$ glass coverslips to $70 \%$ confluency. For imaging, coverslips were fixed with $4 \%$ Paraformaldehyde and permeabilized with perm/wash buffer from BD Biosciences (San Jose, CA, USA). Hybridization with primary antibodies was done using perm/wash solution in humidified chambers. For mitochondria staining we used MTC02 (Abcam 3298) at 1:500 dilution overnight, followed by a secondary TRITC-conjugated antibody at 1:1000 for $1 \mathrm{~h}$. BODIPYTM 493/503 (Thermo Fisher, Waltham, MA, USA) was used at 1:1000 dilution for $10 \mathrm{~min}$ to stain lipid droplets. Phalloidin-Alexa 488 (Thermo Fisher, Waltham, MA, USA) was used at 1:1000 dilution to demarcate the cell perimeter and identify individual cells. DAPI was used to stain the nucleus. Images were taken with an Olympus FV1000 laser scanning confocal via a 100× UPlanSApo oil objective in the Advanced Light Microscopy Core at University of Colorado Denver, Anschutz Medical Campus (Aurora, CO, USA). Analysis was done with free software FIJI (https://imagej.nih.gov/ij/), using the ROI feature to identify individual cells and measuring the mitochondria (red) and lipid (green) channels. A minimum of 20 measurements were done per condition.

\subsection{Lentivirus Preparation and Transfection}

Lentiviral particles for shRNA and ORF (complete open reading frame) specific to CPT1A were prepared at the Functional Genomics facility at the University of Colorado AMC. The following shRNAs from the Sigma shRNA library were used: TRCN0000036279 (CPT1A-KD) and control shRNA (NTshRNA) was SHC202. For CPT1A overexpression (CPT1A-OE), we used the ccsbBroad304-00359 clone from the CCSB-Broad lentiviral library.

\subsection{Reverse-Transcriptase- $P C R$}

For RT-PCR analysis, cDNA was synthesized (Applied Biosystems, Foster City, CA, USA) and quantified by real-time PCR using SYBR green (BioRad, Hercules, CA, USA) detection. Results were normalized to the housekeeping gene RPL13A mRNA and expressed as arbitrary units of $2^{-\Delta \Delta C T}$ relative to the control group. A list of primers used is shown in supplementary Table S1.

\subsection{Mouse Xenograft Studies}

Mice were purchased from Charles Rivers Labs and surgically castrated before cell inoculations under the skin. We used NTsh (control for KD), CPT1A-KD, EV (control for OE) and CPT1A-OE cell lines from C4-2 and 22Rv1 models to generate the xenografts. NSG mice were used for the C4-2, 
and nu/nu mice for $22 \mathrm{Rv} 1$ cells. About $2 \times 10^{6}$ cells were inoculated per flank, and tumor growth was monitored daily with calipers. For MDV3100 (enzalutamide or Enza) studies, tumors were generated the same way, and when they reached $\sim 500 \mathrm{~mm}^{3}$, we initiated oral treatment with Enza at $20 \mathrm{mg} / \mathrm{Kg}$ every other day for 3 weeks. Tumor growth was calculated using the formula volume $=(\pi \times$ length $\times$ width $\left.{ }^{2}\right) / 6$.

\subsection{Western Blot Analysis}

Protein extracts of $20 \mu \mathrm{g}$ were separated on a 7.5\% SDS-PAGE gel and transferred to nitrocellulose membranes, as described [19]. The same protein lysates were probed on different blots. Antibodies to all the histone acetylation marks were purchased from CST (Boston, MA, USA), and are shown in supplementary Table S2. Band signals were visualized with the LICOR system (Lincoln, NE, USA).

\subsection{Histone Isolation and Mass Spectrometric Analysis}

Histones were isolated from cells grown in FBS or CSS supplemented with $50 \mathrm{uM} \mathrm{C}^{13}$-acetate (Sigma Aldrich, St. Louis, MO, USA) for $48 \mathrm{~h}$. Isolation was done with a histone isolation kit (Abcam 113476, Cambridge, MA, USA), and then run in a 20\% SDS PAGE gel to separate the histones from other nonhistone proteins. Excised histone gel pieces were destained in ammonium bicarbonate $/ 50 \%$ acetonitrile and dehydrated in 100\% acetonitrile. Mass Spectrometric (MS) analysis was done at the CU School of Medicine's Biological Mass Spectrometry Core. Digestion, peptide isolation, and MS analysis are described in detail in the supplementary methods section. Scaffold (Proteome Software v4.8, Proteome Software Inc., Portland, OR, USA) was used to validate MS/MS-based peptide and protein identifications. Peptide identifications were accepted if they could be established at greater than $95.0 \%$ probability, as specified by the Peptide Prophet algorithm. Protein identifications were accepted if they could be established at greater than $99.0 \%$ probability and contained at least two identified unique peptides.

\subsection{Statistics}

Student $t$-tests or ANOVA tests were used to compare between groups, followed by post hoc tests when appropriate. Corrections for multiple comparisons were done with Holm-Sidak method, alpha $=0.05$. Analysis was carried out with GraphPad Prism software (v7, La Jolla, CA, USA). All data represent mean \pm SD unless otherwise indicated.

\subsection{Clinical Data Analysis}

Prostate cancer datasets, comprising 3313 patients/3542 samples in 16 studies (PMID: 22722839, 26000489, 26855148, 23622249, 22610119, 28068672, 26928463, 20579941, 25024180, 29610475, 28927585, 26544944, 25201530, 28825054, 29622463, 29625055, 29625050, 29625048, 29617662, 29596782) were queried for CPT1A amplification on cBioportal (cbioportal.org). Three datasets (TCGA Cell 2015, TCGA PanCancer, and TCGA Provisional) were not included in the analysis as they had overlapping data with other selected studies. Cancer study and cancer-type detailed summaries and survival outcomes have been reported here.

\section{Results}

\subsection{Characterization of CRPC C4-2 Cells with CPT1A Knock-Down (KD) or Overexpression (OE)}

In order to elucidate the role of CPT1A in CRPC, we generated LNCaP-C4-2 cells with decreased and increased CPT1A expression using lentivirus transduction. The KD cells were generated with the same shRNA that was recently used in LNCaP cells in a previous publication [18]. We chose the C4-2 cell line because it is an established model of the castration-resistant phenotype observed in the clinic. This line was derived from the hormone-sensitive LNCaP cells and was grown in castrated nude mice for more than 12 weeks [27]. Another important aspect is that this model lacks the tumor suppressor 
PTEN, which is commonly lost in prostate cancers [28]. Figure 1A,B show the CPT1A mRNA and protein of the C4-2 generated cell lines, including their respective controls. As expected from our previous studies [18,19], the KD cells showed less clonogenic growth (Figure 1C,D), but surprisingly, the OE cells showed a similar trend. We then performed migration studies to study if CPT1A is needed for cell motility. Only the KD cells were possible to analyze since the OE cells did not attach well, and it was therefore difficult to assess migration into the scratch gap (Figure 1E). Since the OE cells grew better in suspension, we performed growth suspension assays on low-attachment plates. We observed a modest but significant increase in the diameter of the OE spheres compared with controls (Figure 1F). Thus, the decreased clonogenic growth in the OE cells in a two-dimensional (2D) model (Figure 1C) was not observed in a forced suspension culture.

A

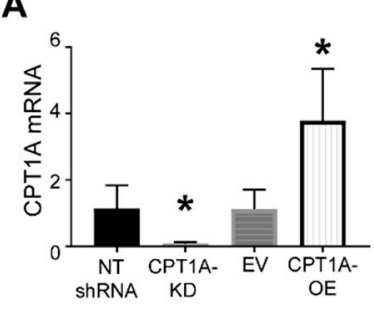

B

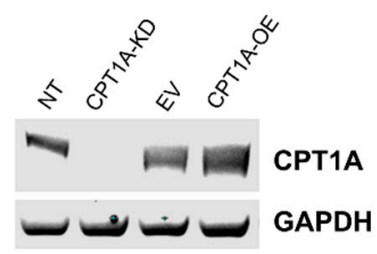

C
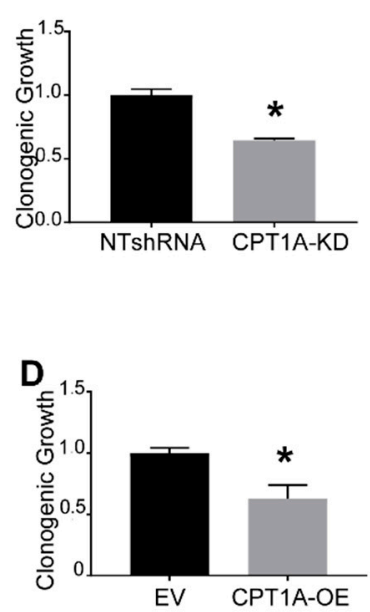

E

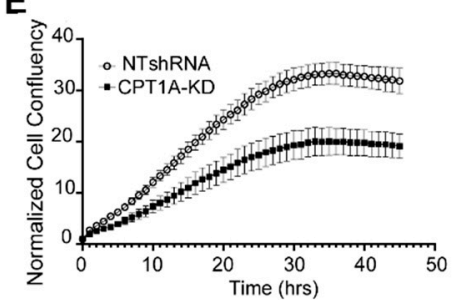

$\mathbf{F}$

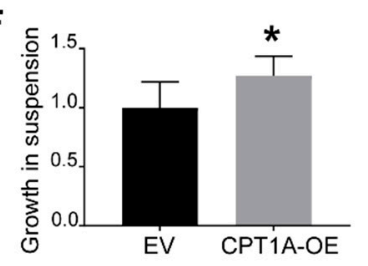

Figure 1. Characterization of $C 4-2$ cells with $C P T 1 A$ knock-down (CPT1A-KD) or CPT1A overexpression (CPT1A-OE). (A): CPT1A mRNA levels were measured in CPT1A knockdown and overexpressing C4-2 cells using qRT-PCR, ( $\mathrm{n}=4$ per group. Students $t$-test; ${ }^{*} p=0.002$ for $\mathrm{KD}$ and ${ }^{*} p=0.007$ for OE). Each measurement was normalized to corresponding RPL13A mRNA. (B): Representative western blots showing the protein level of CPT1A in CPT1A-KD, CPT1A-OE and their respective controls (NTshRNA, $\mathrm{EV})$ in C4-2 cells. GAPDH was used as loading control. (C,D): Clonogenic growth of CPT1A-KD (C) and CPT1A-OE (D) compared with their respective controls ( $\mathrm{n}=4$ per group, Students $t$-test. ${ }^{*} p<0.01$ vs. controls). (E): Scratch wound / migration assay on Essen IncuCyte ${ }^{\circledR}$. Cell migration was measured by cell confluency ( $\mathrm{n}=10$ per group). The scratch area at time 0 was set to 1 . Representative images are in Supplementary Figure S1A. Similar experiments with CPT1A-OE cells did not yield usable data, as they did not adhere firmly, resulting in nonuniform scratch lines that could not be measured reliably. (F): Growth assay in suspension conditions with CPT1A-OE cells and control cells. CPT1A-OE and control EV cells were plated in low-adherence plates in complete media with serum for 14 days; $\mathrm{n}=8$ per group, ${ }^{*} p=0.014$ vs. control. Representative images in Supplementary Figure S1B.

Since CPT1A resides in the outer membrane of the mitochondria, we imaged mitochondria (red) and lipid droplet content (green) of the cells (Figure 2). Overall, we did not see significant changes in mitochondria in both cell lines, but lipid droplets were significantly increased in CPT1A OE cells. On the other hand, there was a significant decrease in lipid droplets in the KD cells, perhaps associated with a less aggressive phenotype. Next, we studied if the ability to accumulate lipid and its oxidation were correlated in CPT1A OE cells. The ability to burn long-chain fatty acids like oleic and palmitate, which need CPT1A to get into the mitochondria as acyl-carnitines, was assessed with Seahorse mito stress test assays (Figure 2E). The OE cells had an increased basal oxygen consumption rate (OCR) for these common long lipids (first three points in graph) and increased maximal respiration rate (after FCCP addition). There were no changes observed when fat-free albumin vehicle controls were used (supplementary Figure S1C). Furthermore, when we supplemented cells with medium-chain fatty 
acids, which are less dependent on CPT1A to enter the mitochondria, we also observed increased OCR, indicating an overall increased ability to burn lipid in the OE cells (supplementary Figure S1). Our previous work demonstrated that CPT1A KD cells have decreased ability to burn lipids [18,29].

A
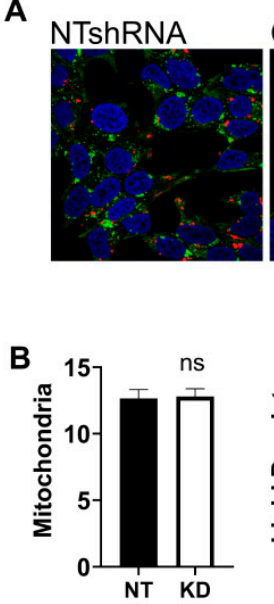

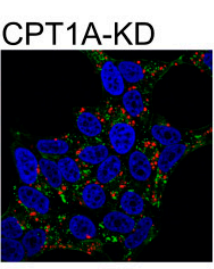

$\mathrm{c}_{\mathrm{EV}}$

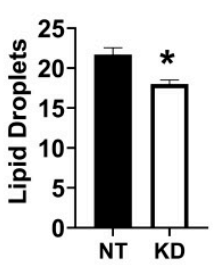

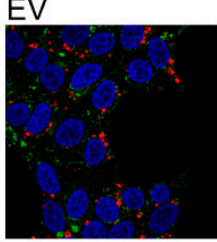

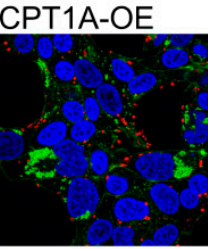

D
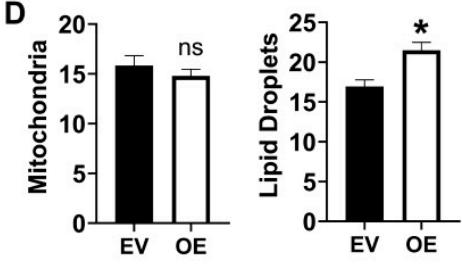

E
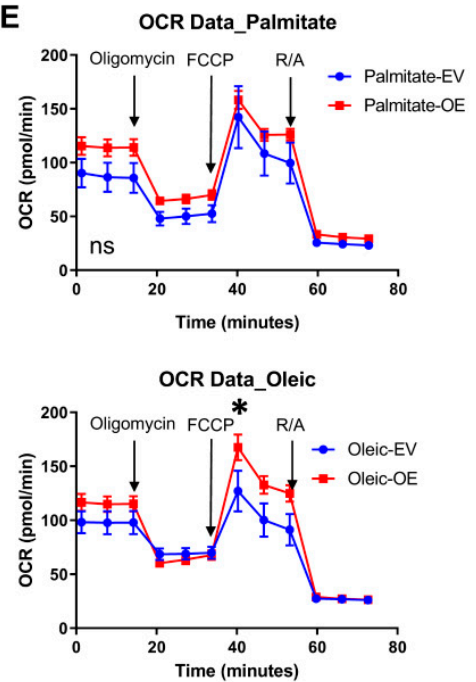

Figure 2. Phenotypic characterization of C4-2 CPT1A-KD and CPT1A-OE cells. (A-D): Mitochondrial and lipid droplet staining in CPT1A-KD cells $(\mathbf{A}, \mathbf{B})$ and CPT1A-OE cells $(\mathbf{C}, \mathbf{D})$. Cells were stained for lipid droplets (green), mitochondria (red), and nuclei (blue). A minimum of 20 cells per group were captured and quantitated using ImageJ. ${ }^{*} p<0.01$ vs. control. (E): Oxygen Consumption Rate (OCR) of C4-2 CPT1A-OE and control EV cells $(\mathrm{n}=10$ each) was measured using the Seahorse XFe96 Analyzer. Cells were serum-starved overnight and then incubated with the BSA-conjugated fatty acids (palmitate or oleate) $1 \mathrm{~h}$ before the assay. Traces shown correspond to Cell Mito Stress protocol, using Oligomycin $(2 \mathrm{uM}), \mathrm{FCCP}(2 \mathrm{um})$ and rotenone/antimycin A $(1 \mathrm{uM})$ at 20,40 , and $60 \mathrm{~min}$ respectively, $p^{*}=0.012$ compared with EV control. Seahorse graphs show mean \pm SEM.

3.2. The CPT1A KD cells Show Increased Response to Androgens, While CPT1A OE Cells Show a More AR-Independent Phenotype

Previously, we observed that LNCaP cells with CPT1A KD showed increased expression of androgen-response hallmark genes [19]. To test if this was still the case in CRPC cells, we examined the expression of several androgen-regulated genes in the C4-2 KD and OE cells. As shown in Figure 3, KD cells showed increased expression of these AR-regulated genes, while the OE cells did not. In fact, when we supplemented the cells with $100 \mathrm{pM} \mathrm{DHT} \mathrm{(dihydrotestosterone),} \mathrm{we} \mathrm{observed} \mathrm{a} \mathrm{significant}$ increase in AR full length (5-fold) and variant ARv7 (9-fold) in the KD cells, but not in the OE cell (Figure 3C). To ascertain if these results could be recapitulated in other genetically different CRPC cells, we generated 22Rv1 CPT1A KD and OE cells (supplementary Figure S2). We chose the 22Rv1 cells because they represent a good model of CRPC that has increased AR and ARV7 expression, but it is PTEN positive, so the AKT pathway is not always activated like in the C4-2 cell line [30,31]. Thus, the 22Rv1 offer a complementary model to the C4-2 cells used in the studies above. The 22Rv1 KD cells grew less in 2D clonogenic assays, like the C4-2 cells, but this effect was not seen in the 22RV1 OE cells, which showed no significant changes in clonogenic or growth in suspension compared with control cells. The migration capacity of the $22 \mathrm{Rv} 1 \mathrm{KD}$ cells was also reduced, like in the C4-2 KD cells, supplementary Figure S2. Regarding the lipid-burning capacity, 22Rv1 OE cells also showed increased OCR by seahorse assays with long-chain fatty acids, suggesting a functional CPT1A overexpressed enzyme. This lipid-induced OCR was suppressed by CPT1A inhibition with etomoxir at the start of the assay (supplementary Figure S3). However, regarding AR expression, we did not observe the dramatic increases in AR-FL and ARV7 in the 22Rv1 KD cells compared with the C4-2 cells, suggesting fundamental differences in the androgen response in the 22Rv1 cells (supplementary Figure S3G). 
Alternatively, the abundance of AR isoforms in the 22RV1 cells could make them refractory to large changes in AR. Lastly, lipid droplet and mitochondria stains were also different from the C4-2 cells, since the 22Rv1 cells had very few lipid droplets but abundant mitochondria compared with the C4-2 cells. Interestingly, less mitochondria were observed with both the KD and the OE cells compared with their respective controls (supplementary Figure S4).

A
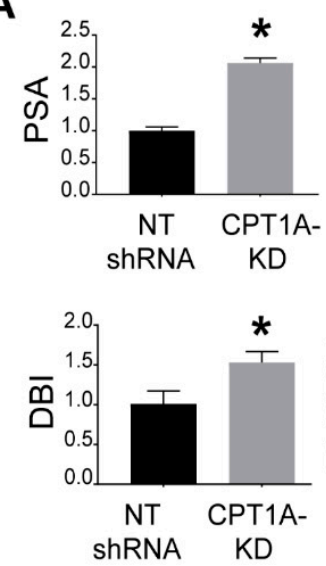

B
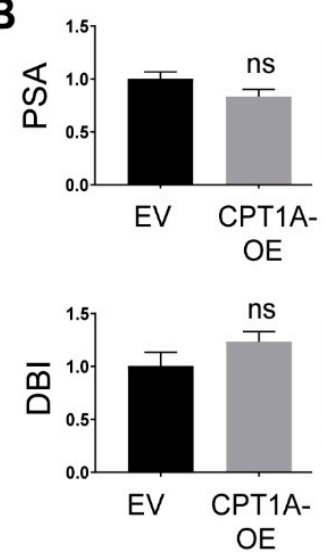
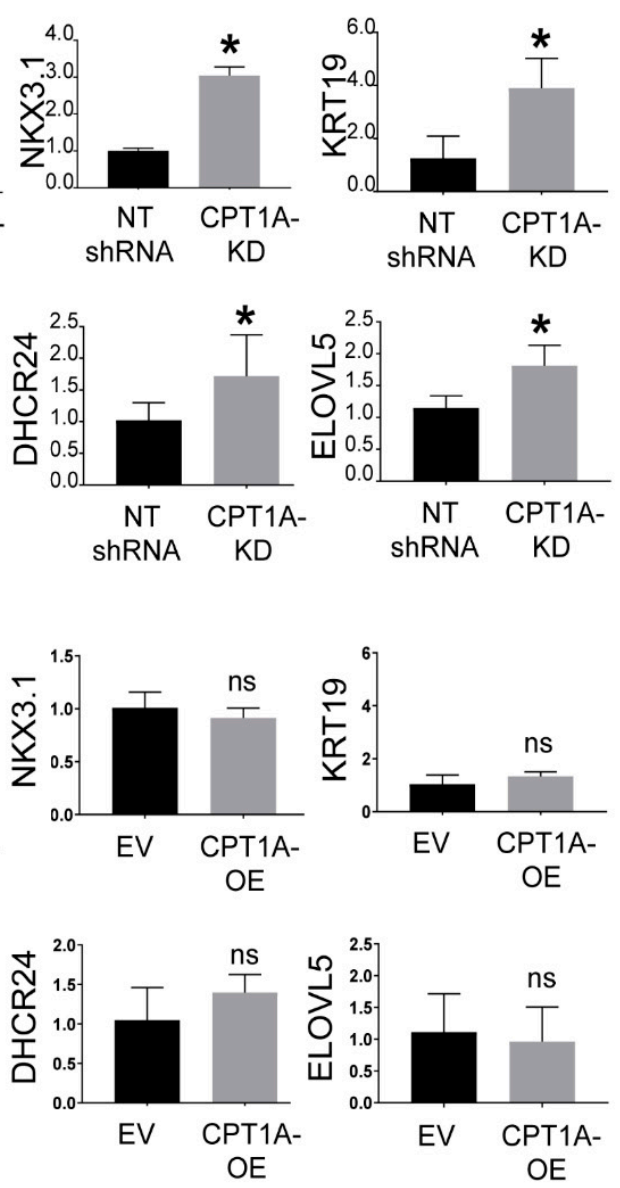
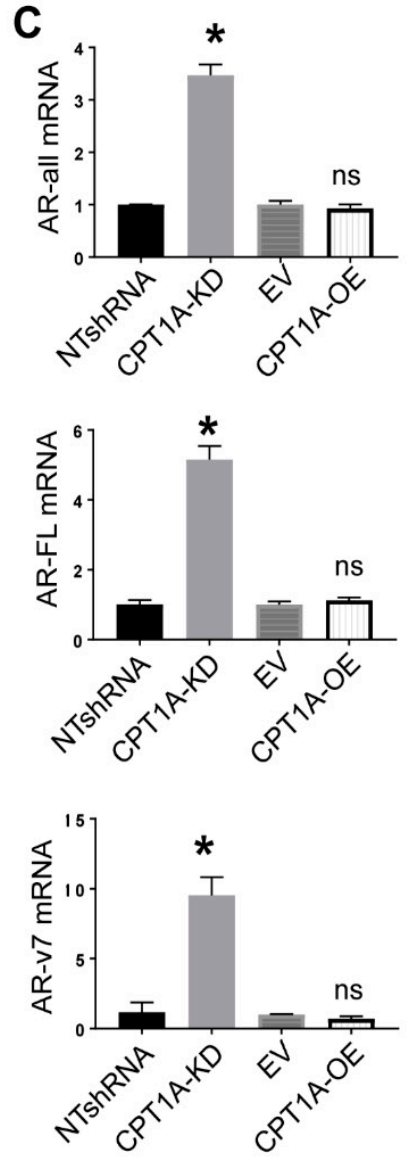

Figure 3. AR response in C4-2 CPT1A-KD and CPT1A-OE cells. (A): Basal expression of AR response genes in C4-2 CPT1A-KD and control NTshRNA cells, $\mathrm{n}=4$ per group; Students $t$-test. ${ }^{*} p<0.01$ vs. control. (B): Basal expression of AR response genes in C4-2 CPT1A-OE and control EV cells. Data was normalized to RPL13A mRNA, $n=4$ per group, changes were not significant. (C): AR mRNA expression in response to DHT. Expression of AR-all (measures all isoforms of AR), ARFL (full length $\mathrm{AR}$ ) and ARv7 (AR variant v7) was measured in response to $100 \mathrm{pM}$ DHT in CPT1A-OE and control EV cells, $\mathrm{n}=4$ per group. ${ }^{*} p \leq 0.01$ compared with its respective control.

Next, we studied the effect of androgen stimulation on clonogenic growth at increasing doses in the C4-2 and 22Rv1 cells (Figure 4). The most salient results were that both the C4-2 and 22Rv1 KD cells showed increased growth compared with controls in the presence of DHT (Figure 4A,D, respectively). On the other hand, C4-2 OE cells showed a significant decrease in growth (Figure 4B), whereas no significant changes were observed in the 22Rv1 OE cells. To examine the effect of the anti-androgen enzalutamide in the $\mathrm{OE}$ cells, we studied their growth in the presence of increasing doses of enzalutamide. The C4-2 OE cells showed significant resistance to enzalutamide compared with controls (Figure 4C), while the 22Rv1 OE cells showed a more modest drug resistance trend (Figure 4F). A previous report by us [19] already showed that KD cells have increased sensitivity to enzalutamide in vitro. 
A

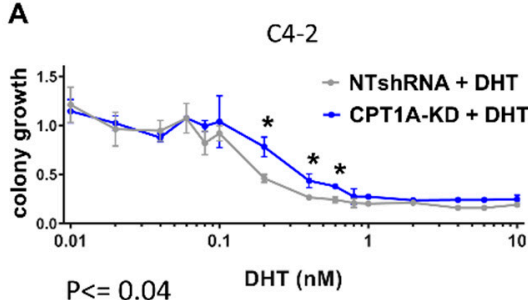

D

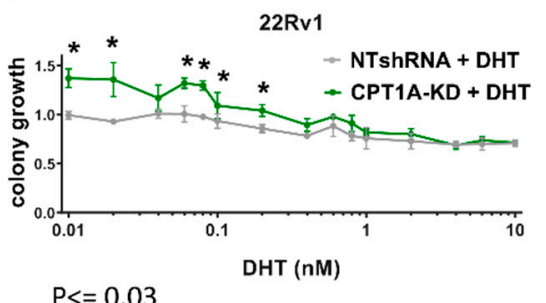

B

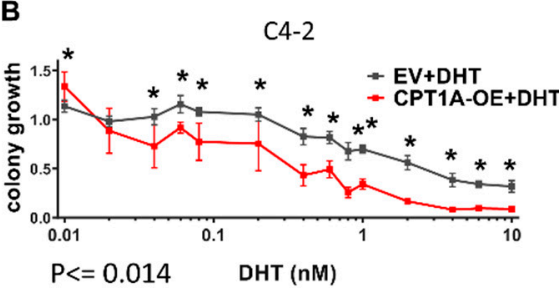

E

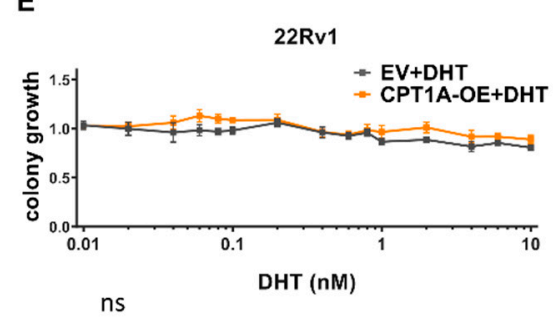

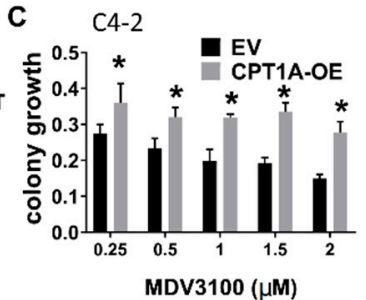

$\mathbf{F}$

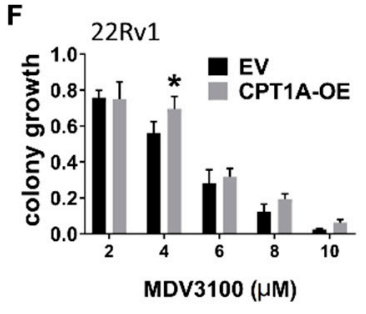

Figure 4. Clonogenic growth of $C P T 1 A-\mathrm{KD}$ and $C P T 1 A-\mathrm{OE}$ cells in the presence of androgens or anti-androgens. Cells were grown in media containing FBS supplemented with increasing DHT (androgen) or MDV3100 (enzalutamide) concentrations. Colonies were analyzed by normalizing to vehicle treatments. Significant results between conditions are indicated: $(A-C)$ : Clonogenic growth of C4-2 CPT1A-KD and control cells (A) and C4-2 CPT1-OE and control cells (B) in presence of increasing amounts of DHT, $\mathrm{n}=4$ per group. (C) Clonogenic growth of C4-2 CPT1-OE and control cells with increasing concentrations of MDV3100, $\mathrm{n}=4$ per group, ${ }^{*} p<0.01$. vs. control. (D-F): Clonogenic growth of 22Rv1 CPT1A-KD and control (D) and 22Rv1 CPT1-OE and control (E) with increasing amounts of DHT, $\mathrm{n}=4$ per group. (F) Clonogenic growth for the 22Rv1 CPT1-OE and EV control cells with increasing concentrations of MDV3100, $\mathrm{n}=4$ per group, ${ }^{*} p=0.01$ vs. control.

\subsection{CPT1A Expression in Tumors Modulates Growth and Response to Enzalutamide in Castrated Mice}

The response of the KD and $\mathrm{OE}$ cells to enzalutamide in vitro inspired us to evaluate the growth of KD and OE cells in a castrated mouse model, mimicking the environment of the CRPC in the clinical setting (Figure 5). The C4-2 and 22Rv1 KD cells showed a modest decrease in tumor growth over time (Figure 5A,C, respectively). However, the C4-2 and 22Rv1 OE tumors showed significant increased growth (Figure 5E,G, respectively). These results underscore how the absence of androgens promotes the growth of the CPT1A OE tumors. Next, we challenged a new set of well-established tumors with oral enzalutamide for approximately 3 weeks. The C4-2 CPT1A KD cells showed a significant decrease in growth compared with control tumors (Figure 5B), and this effect was also observed in the 22Rv1 KD model, albeit more modestly (Figure 5D). Regarding the C4-2 and 22RV1 CPT1A OE cells, both tumor models showed increased growth compared with controls (Figure 5E,G, respectively). Treatment with enzalutamide did not decrease the growth of the OE cells, in fact it seemed to enhance the growth of the tumors (Figure 5F,H). Thus, in the absence of androgens and with AR blockade, CPT1A overexpression provides a growth advantage to the tumors. 


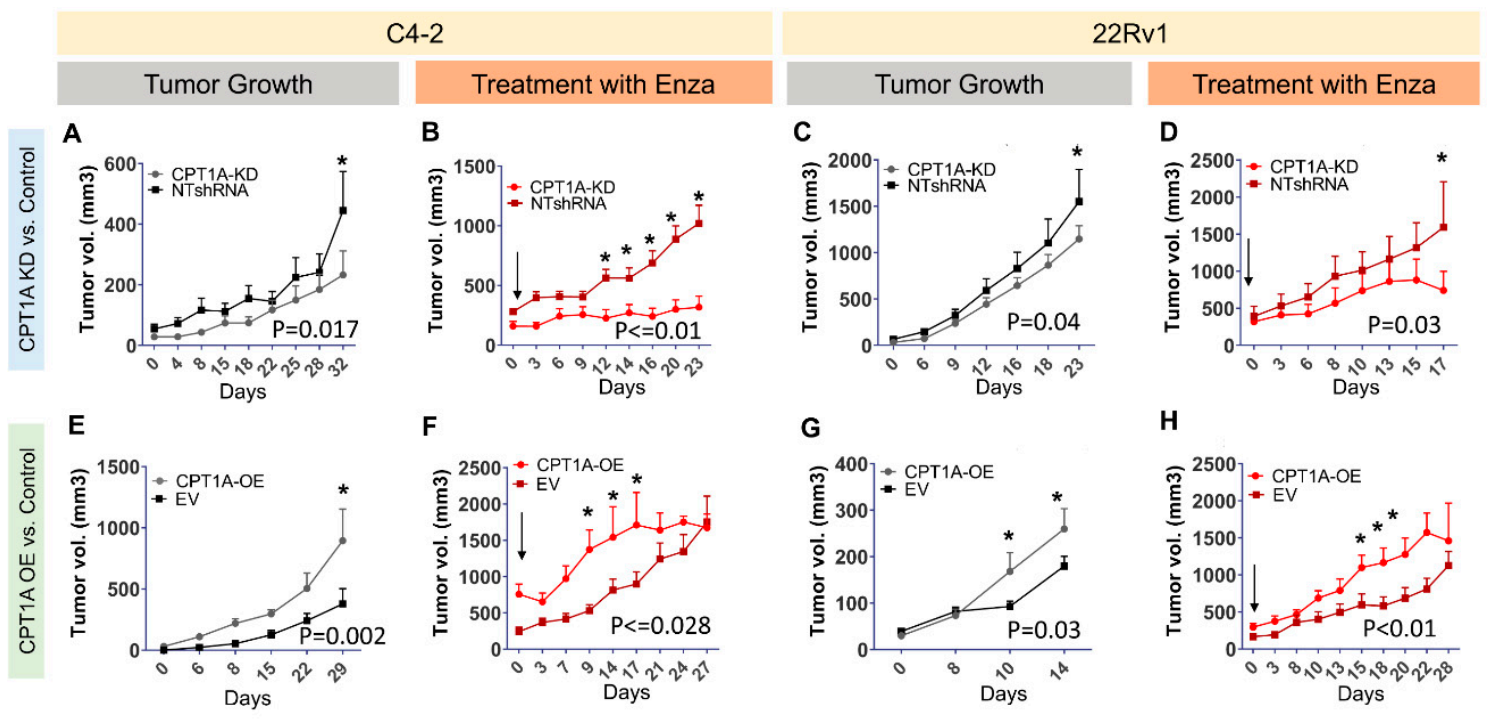

Figure 5. $C P T 1 A$ expression in tumors modulates their growth and the response to enzalutamide in castrated mice. NSG mice were used for the C4-2 cells and nu/nu mice for $22 \mathrm{Rv} 1$ cells. Mice were castrated 2 weeks before cell implantations. Figures (A) and (C) show tumor growth curves for C4-2 and 22Rv1 with CPT1A-KD and control NT-shRNA cells, respectively. Similarly, Figures (E) and (G) show tumor growth curves for C4-2 and 22Rv1 with CPT1A-OE and EV control cells, respectively. In separate experiments, mice received oral gavage of $20 \mathrm{mg} / \mathrm{kg}$ enzalutamide (Enza) once tumors were established and growing $(\geq 300 \mathrm{cc}$ ). Figures (B) and (D) show response to Enza in tumors with CPT1A-KD, whereas figures $(\mathbf{F})$ and $(\mathbf{H})$ show response to Enza in tumors overexpressing CPT1A (OE). Significance differences are indicated $\left(^{*}\right)$ for each group. Mouse numbers per graph: $(\mathrm{A}):(\mathrm{NT}=11$, $\mathrm{KD}=13),(\mathbf{B}):(\mathrm{NT}=5, \mathrm{KD}=5),(\mathrm{C}):(\mathrm{NT}=12, \mathrm{KD}=14),(\mathrm{D}):(\mathrm{NT}=5, \mathrm{KD}=5),(\mathrm{E}):(\mathrm{EV}=8, \mathrm{OE}=8)$, $(\mathbf{F}):(\mathrm{EV}=6, \mathrm{OE}=6),(\mathrm{G}):(\mathrm{EV}=7, \mathrm{OE}=7),(\mathrm{H}):(\mathrm{EV}=5, \mathrm{OE}=5)$.

\subsection{CPT1A Expression Modulates Histone Acetylation in An Androgen-Dependent Manner.}

Studies in liver cells have shown that fat oxidation can provide up to $90 \%$ of acetyl carbon for histone acetylation and gene expression modulation [25]. In order to identify possible epigenetic changes that could mediate the connection between CPT1A and AR, we examined the acetylation status of the C4-2 cells (Figure 6). We examined the lysine acetylation pattern of whole cell lysates of C4-2 CPT1A KD and OE cells in FBS (castrate levels of androgens, [32]) and CSS (androgen-deprived) conditions (Figure 6A). We observed increased global lysine acetylation in the CSS condition, especially in the OE cells, likely due to the increased CPT1A activity and acetyl-CoA production. Next, we studied histone acetylation patterns by western blot (Figure 6B). A Coomassie stain of the isolated histones is shown in supplementary Figure S5. The most dramatic difference was observed in Histone 3 Lysine 9 acetylation (H3K9ac); the OE cells showed increased acetylation in CSS compared with controls, but the opposite was seen under FBS conditions. In contrast, there was a significant increase in acetylation of H3K9 in KD cells in FBS, but a dramatic reduction of the mark in CSS conditions compared with the control lysates. Other histone acetyl marks like H3K14, K18, K27, and H4K8 also showed a similar trend of decreasing in KD and OE cells in FBS. Interestingly, we continued to see a decrease in acetylation of $\mathrm{H} 3 \mathrm{~K} 14, \mathrm{~K} 18, \mathrm{~K} 27$, and H4K8 in KD cells in CSS conditions, while the OE cells showed either no change or modest increase (exception in $\mathrm{H} 4 \mathrm{~K} 8$ ), reflecting global acetylation changes. These data point to a modulatory role of androgens on CPT1A activity and downstream acetylation events. Additional histone acetylation marks are shown in supplementary Figure S5. 
A

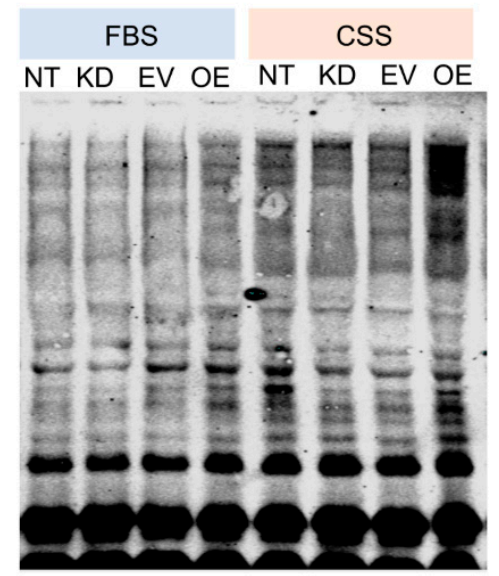

B

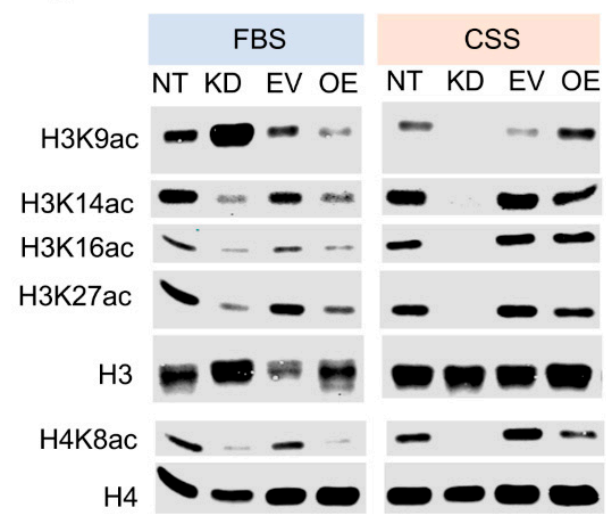

C
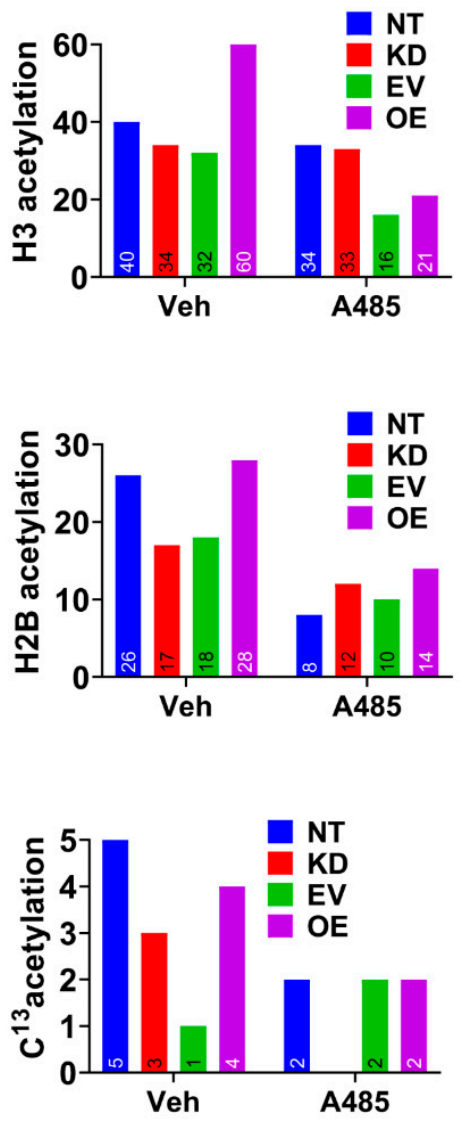

Figure 6. $C P T 1 A$ expression modulates histone acetylation in an androgen-dependent manner. (A): Representative western blot of cell lysates with pan-acetylated lysine antibody. (B): Western blot analysis of acetylated histone lysine residues from C4-2 cells (KD and OE) cultured in FBS or CSS (steroid- free media). (C): Lysine acetylation of histones $\mathrm{H} 3$ and $\mathrm{H} 2 \mathrm{~B}$, isolated from $\mathrm{C} 4-2$ cells cultured in CSS, with or without p300 inhibitor A485 $(5 \mu \mathrm{M})$, and measured by mass spectrometric analysis. Additionally, cells were treated with $\mathrm{C}^{13}$-acetate for $24 \mathrm{~h}$ in CSS with or without A485, followed by histone isolation and mass spectrometric analysis. Numbers on bars indicate amount of specific 13C-acetylated histone peptides identified.

To study the labeling of histones according to CPT1A expression by mass spectrometry, we treated cells grown in CSS with $\mathrm{C}^{13}$-acetate to follow the fate of the acetate carbons in histones. Acetate is carbon form that is readily picked up by tumor cells and significantly contributes to the pools of acetyl-CoA in the cell [33]. Figure 6C shows the overall acetylation for Histone 3 and Histone 2B in the C4-2 cells, as well as all the $\mathrm{C}^{13}$-labeled histones. The H3 and H2B were the histones in which we observed the most acetylated peptide counts. Less numbers of $C^{13}$-labeled histone peptides were observed, but they seemed to follow the same pattern as the non-labeled ones. When the same experiment was conducted in the presence of A485, a potent selective inhibitor of p300 and CBP that competes with acetyl-CoA [34], we observed a global decrease in histone acetylation under the same conditions, suggesting that de novo $\mathrm{C}^{13}$-acetylation of histones was taking place in CSS conditions.

To study the relevance of CPT1A expression in advanced PCa, we mined the cBioportal database that now includes more metastatic and aggressive tumors. Figure 7A shows all PCa studies with CPT1A amplification data; a total of 3542 samples from 3313 patients across 16 studies were queried for CPT1A amplification. CPT1A was amplified in 4\% (116) patients and 4\% (124) samples. Classification of this same data by PCa types clearly showed that CPT1A was amplified in $21.43 \%$ of CRPC and $16.67 \%$ of neuroendocrine carcinomas compared with $2.99 \%$ PCa adenocarcinomas (Figure 7B), suggestive 
of a correlation between $C P T 1 A$ overexpression and more aggressive prostate cancer. We further evaluated this data set for overall patient survival outcome (patient survival data was available for only 484 patients). CPT1A was amplified in 17 out of 484 patients, and of these 17 patients, 13 were deceased with a median survival of 17.6 months. This was statistically significantly lower $\left(p=8.52 \times 10^{-11}\right)$ compared with the cohort of patients with no alteration in CPT1A; this group consisted of a total of 467 patients, including the 120 deceased, whose median survival time was 120 months. Overall, the Kaplan Meier curve suggested that patients with amplified CPT1A had significantly poorer outcome. Due to the small sample size and insufficient data for each sample, we were not able to parse this further to look for links among CPT1A amplification, cancer type, and survival outcome.

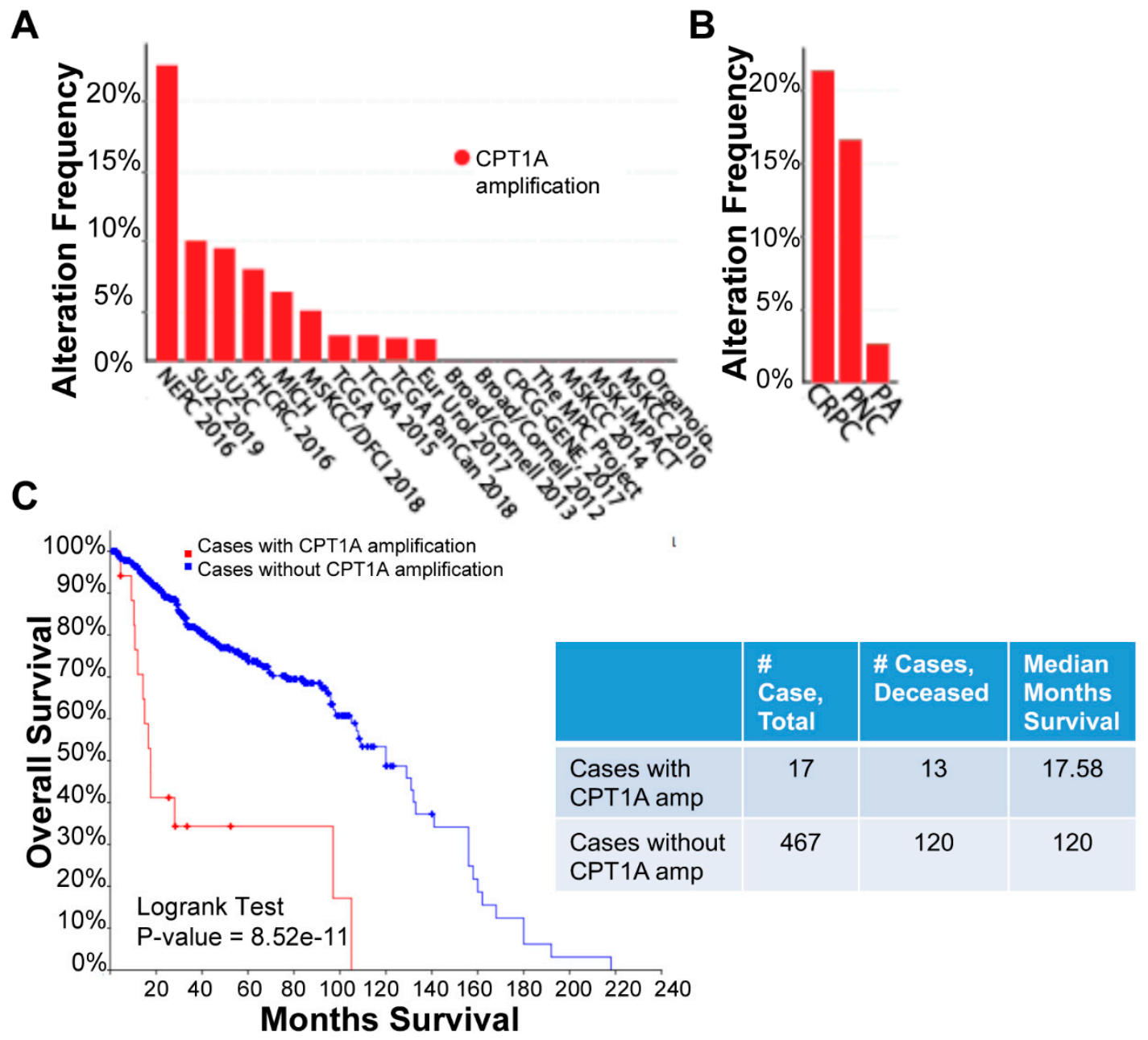

Figure 7. $C P T 1 A$ amplification in prostate cancer across 16 publicly available studies. Data shown represents analysis of cBioportal database. A total of 3542 samples from 3313 patients across 16 studies were queried for CPT1A amplification (A): Graph shows frequency of CPT1A amplification across the studies. (B): Same data as in A, but reorganized according to PCa type: PA, prostate adenocarcinoma; NPC, neuroendocrine; CRPC, castration-resistant PCa. (C): Kaplan Meier curve showing overall survival for 484 patients. Red line shows cases with CPT1A amplification. Table shows the number of deceased cases and median months survival according to $C P T 1 A$ amplification status.

\section{Discussion}

Understanding lipid metabolism in CRPC can open doors to new and improved therapies. In this report, we focused on the role of CPT1A in supporting CRPC growth in an androgen-dependent manner. We found an inverse relationship between $C P T 1 A$ expression and androgen responsiveness in our models. Specifically, androgen withdrawal promoted the growth of CPT1A-OE tumors 
while it decreased the growth of CPT1A-KD tumors and increased their sensitivity to enzalutamide. This association is important, since CRPC remains lipid- and AR-dependent [35], but the use of potent anti-AR drugs like enzalutamide have a limited response and virtually all patients fail and develop resistance $[7,8]$. Our results open opportunities to target lipid oxidation in the mitochondria and AR signaling in the nucleus simultaneously, as a more effective therapy or perhaps a more durable response to anti-androgens.

Since CPT1A is not an oncogene, but a liver enzyme also abundant in epithelial cancers [36], finding its role in cancer has not been intuitive, especially since most cancers have a strong dependency on glucose and rely on the Warburg effect [37]. In the case of PCa, there is more dependency on lipids for growth and survival, which makes the FDG-PET imaging not effective in diagnosis and staging [29]. However, successful tumors that survive the metastatic process and drug treatments become more resilient and adapted to harsh environments. They do this by increasing their dependency on metabolic enzymes like CPT1A, which can lead to production of ATP, antioxidants, and metabolic intermediates that sustain growth and drug resistance $[22,23,38,39]$. Recently, as the PCa databases have become more complete, $C P T 1 A$ is emerging as a potential biomarker of patient survival in advanced PCa. The present study provides clues as to how CPT1A contributes to CRPC and AR activity.

Generating CPT1A-OE cells was challenging since they came off the plates very easily, indicating a tendency to grow better in suspension. The accumulation of lipids observed in CPT1A OE cells is also a characteristic of more aggressive cancers [40-42]. Since these cells also had more lipid-burning capacity, it points to the possibility of a lipid cycle where CRPC cells accumulate lipid stores that burn quickly, like a seemingly futile cycle, but one that promotes survival. In fact, targeting both lipid synthesis and lipid oxidation simultaneously could be an interesting approach to decrease CRPC growth and progression [18].

The increased growth of the $C P T 1 A-K D$ cells under androgen stimulation suggested the modulatory role of androgens in CPT1A activity and revealed a reciprocal association (Figure 4) that could be therapeutically exploited. In fact, in castrated mice, CPT1A-KD tumors grew less and were more sensitive to enzalutamide, which could be due to a compensatory upregulation of the androgen response to try to restore lipid beta-oxidation. This upregulation could make the cells more sensitive to androgens for growth, and more sensitive to the anti-androgens. On the other hand, CPT1A-OE cells and tumors showed the opposite effect; growth inhibition with androgens and growth stimulation with androgen depletion (Figures 4 and 5). These results suggest that CPT1A expression is important for growth in androgen-depleted conditions, but remains modulated by androgens since increasing doses of DHT decreased growth of CPT1A-OE cells (Figure 4). We cannot rule out the possibility that CPT1A-OE cells remain sensitive to very small doses of androgens, with a very low threshold of AR activity. This phenomenon has been observed by reducing prohibitin in PCa cells, resulting in increased histone acetylation and sensitization cells to low levels of androgens, [43]. The possibility that these low levels of androgens are generated from cholesterol stored in lipid droplets is also very plausible [44], and remains to be studied in CPT1A-OE cells. These results may have implications for recent trials where androgen supplementation was used to treat CRPC by exploiting the androgen-repressive functions at supraphysiological levels [45]. Our results suggest that CPT1A could be a biomarker to stratify patients that will respond to such hormonal challenges.

In this work, we offered a potential pathway of communication between CPT1A activity and nuclear acetylation changes that could explain the growth phenotypes we observed. The increased lysine acetylation in OE cells in castrated (CSS) conditions was expected since excess acetyl-CoA is known to acetylate cytoplasmic proteins [46]. Of note was the enhanced acetylation of H3K9 in the $\mathrm{OE}$ cells in androgen-deprived conditions. This data is further supported by the fact that H3K9ac accompanied by presurgery PSA level has been reported to predict the risk of the biochemical recurrence after radical prostatectomy [47]. However, the dramatic decrease in histone acetylation in KD cells was unexpected (Figure 6). We speculate that this is due to a deficient supply of acetyl-CoA via CPT1A in the absence of androgens, decreasing growth. Another possibility for this decrease in histone 
acetylation in the KD cells is a compensatory activity of HDACs to try to activate AR signaling [48], or perhaps to free-up acetyl groups for energy purposes. Interestingly, in the presence of androgens (FBS), the KD cells had a dramatic increase in H3K9ac signal, suggesting a priming effect of the androgens to stimulate growth, which is what we observed with DHT supplementation (Figure 4). On the other hand, acetylation marks increased in CPT1A-OE cells in ADT conditions, a situation that has been recently associated with CRPC using high-throughput peptide arrays [49], where hyper-acetylation of Histone 3 marks and increased p300 activity in CRPC was observed. Our results suggest that CPT1A supports CRPC by supplying acetyl groups for histone acetylation, promoting growth and anti-androgen resistance. The specific genes modified by these acetylation changes await to be discovered. Figure 8 shows our proposed model for the role of CPT1A overexpression in CRPC.

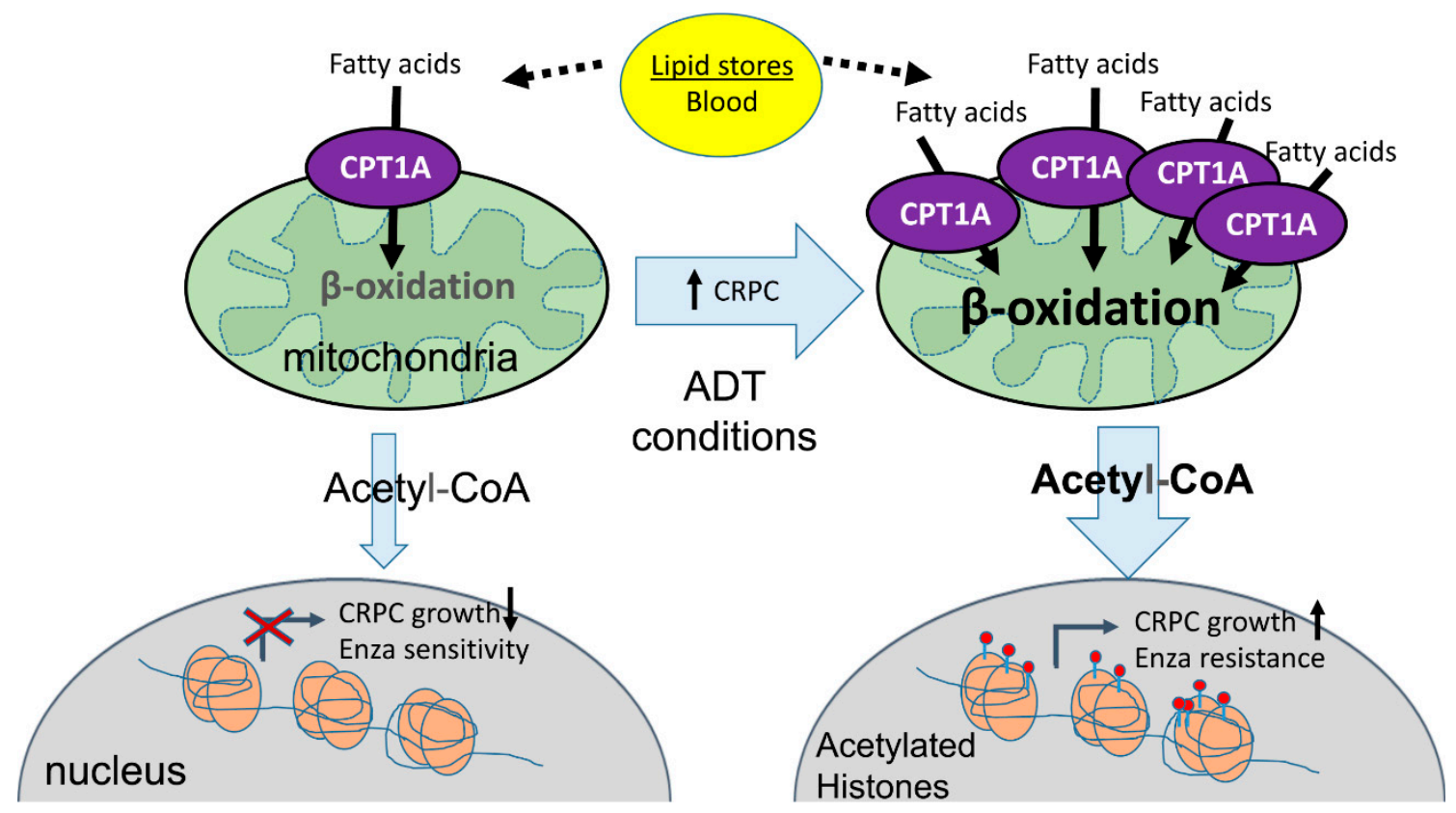

Figure 8. Proposed working model. In castrated conditions, increased CPT1A activity in the mitochondria increases beta-oxidation and generation of acetyl-coA. The excess of acetyl-CoA in the cytoplasm is used by the CRPC cells to acetylate histones and promote increased growth and resistance to anti-androgen therapies like enzalutamide, further promoting the castration-resistant phenotype.

Lastly, in an era of increased utilization of immunotherapies, the role of immune cell metabolism is rapidly increasing. In fact, $\mathrm{T}$ cells use glycolysis to expand and activate, while lipid oxidation via CPT1A keeps them in a suppressed state, unable to attack tumors [50]. These results strongly suggest that metabolic reprograming of the T cells in tumors is a novel Achilles's heel that could be used to re-activate the immune system and invigorate antitumor immunity. The recently reported PROCEED trial including metastatic CRPC patients exposed to sipuleucel-T and enzalutamide [51] opens the door for studying novel sequencing of therapies that could potentially include targeting of CPT1A for optimal treatment.

Supplementary Materials: The following are available online at http://www.mdpi.com/2073-4409/8/10/1115/s1, Figure S1: Supplementary data for Figures 1 and 2 characterizing the C4-2 CPT1A-KD and CPT1A-OE cells. Figure S2: Growth and migration of 22Rv1 cells with CPT1A knockdown and overexpression. Supplementary Figure S3: Seahorse OCR traces and AR isoforms expression in 22Rv1 cells with CPT1A knockdown and overexpression. Supplementary Figure S4: Mitochondrial content of 22Rv1 cells with CPT1A knockdown and overexpression. Supplementary Figure S5: Supplementary data to Figure 6. Table S1: Primer information for RTPCR. Table S2: List of antibodies used in the study. Supplementary methods: Digestion, peptide isolation and MS analysis of histones. 
Author Contributions: Conceptualization, I.R.S.; methodology, I.R.S., M.S.-S., L.N.L., M.D. and M.J.; formal analysis, I.R.S., L.N.L., G.E.S., M.D. and M.J.; Manuscript preparation, I.R.S., M.J. and G.D.; project administration, I.R.S.; funding acquisition, I.R.S.

Funding: This research was funded by the American Cancer Society RSG-16-256-01-TBE.

Acknowledgments: We are thankful to Julianna Oviedo for technical support, and to Jennifer Richer for thoughtful reading of the manuscript.

Conflicts of Interest: The authors declare no conflict of interest.

\section{References}

1. Litwin, M.S.; Tan, H.-J. The Diagnosis and Treatment of Prostate Cancer. JAMA 2017, 317, $2532-2542$. [CrossRef] [PubMed]

2. Attard, G.; Parker, C.; Eeles, R.A.; Schröder, F.; Tomlins, S.A.; Tannock, I.; Drake, C.G.; De Bono, J.S. Prostate cancer. Lancet 2016, 387, 70-82. [CrossRef]

3. Davies, A.; Conteduca, V.; Zoubeidi, A.; Beltran, H. Biological Evolution of Castration-resistant Prostate Cancer. Eur. Urol. Focus 2019, 5, 147-154. [CrossRef] [PubMed]

4. Carver, B.S.; Chapinski, C.; Wongvipat, J.; Hieronymus, H.; Chen, Y.; Chandarlapaty, S.; Arora, V.K.; Le, C.; Koutcher, J.; Scher, H.; et al. Reciprocal feedback regulation of PI3K and androgen receptor signaling in PTEN-deficient prostate cancer. Cancer Cell 2011, 19, 575-586. [CrossRef] [PubMed]

5. Dehm, S.M.; Tindall, D.J. Alternatively Spliced Androgen Receptor Variants. Endocr.-Relat. Cancer 2011, 18, R183-R196. [CrossRef] [PubMed]

6. Taylor, B.S.; Schultz, N.; Hieronymus, H.; Gopalan, A.; Xiao, Y.; Carver, B.S.; Arora, V.K.; Kaushik, P.; Cerami, E.; Reva, B.; et al. Integrative genomic profiling of human prostate cancer. Cancer Cell 2010, 18, 11-22. [CrossRef]

7. De Bono, J.S.; Logothetis, C.J.; Molina, A.; Fizazi, K.; North, S.; Chu, L.; Chi, K.N.; Jones, R.J.; Goodman, O.B.; Saad, F.; et al. Abiraterone and Increased Survival in Metastatic Prostate Cancer. N. Engl. J. Med. 2011, 364, 1995-2005. [CrossRef]

8. Fizazi, K.; Taplin, M.-E.; Sternberg, C.N.; Miller, K.; Flaig, T.W.; Hirmand, M.; Selby, B.; Scher, H.I.; Saad, F.; De Wit, R.; et al. Increased Survival with Enzalutamide in Prostate Cancer after Chemotherapy. N. Engl. J. Med. 2012, 367, 1187-1197.

9. Karantanos, T.; Evans, C.P.; Tombal, B.; Thompson, T.C.; Montironi, R.; Isaacs, W.B. Understanding the Mechanisms of Androgen Deprivation Resistance in Prostate Cancer at the Molecular Level. Eur. Urol. 2015, 67, 470-479. [CrossRef]

10. Saylor, P.J.; Karoly, E.D.; Smith, M.R. Prospective study of changes in the metabolomic profiles of men during their first three months of androgen deprivation therapy for prostate cancer. Clin. Cancer Res. 2012, 18, 3677-3685. [CrossRef]

11. Smith, M.R.; Finkelstein, J.S.; McGovern, F.J.; Zietman, A.L.; Fallon, M.A.; Schoenfeld, D.A.; Kantoff, P.W. Changes in Body Composition during Androgen Deprivation Therapy for Prostate Cancer. J. Clin. Endocrinol. Metab. 2002, 87, 599-603. [CrossRef] [PubMed]

12. Suburu, J.; Chen, Y.Q. Lipids and Prostate Cancer. Prostaglandins Other Lipid Mediat. 2012, 98, 1-10. [CrossRef] [PubMed]

13. Swinnen, J.V.; Brusselmans, K.; Verhoeven, G. Increased lipogenesis in cancer cells: New players, novel targets. Curr. Opin. Clin. Nutr. Metab Care 2006, 9, 358-365. [CrossRef] [PubMed]

14. Swinnen, J.V.; Van Veldhoven, P.P.; Esquenet, M.; Heyns, W.; Verhoeven, G. Androgens markedly stimulate the accumulation of neutral lipids in the human prostatic adenocarcinoma cell line LNCaP. Endocrinology 1996, 137, 4468-4474. [CrossRef] [PubMed]

15. Stoykova, G.E.; Schlaepfer, I.R. Lipid Metabolism and Endocrine Resistance in Prostate Cancer, and New Opportunities for Therapy. Int. J. Mol. Sci. 2019, 20, 2626. [CrossRef] [PubMed]

16. Zadra, G.; Ribeiro, C.F.; Chetta, P.; Ho, Y.; Cacciatore, S.; Gao, X.; Syamala, S.; Bango, C.; Photopoulos, C.; Huang, Y.; et al. Inhibition of de novo lipogenesis targets androgen receptor signaling in castration-resistant prostate cancer. Proc. Natl. Acad. Sci. USA 2018, 116, 631-640. [CrossRef] [PubMed]

17. McGarry, J.D.; Leatherman, G.F.; Foster, D.W. Carnitine palmitoyltransferase I. The site of inhibition of hepatic fatty acid oxidation by malonyl-CoA. J. Biol. Chem. 1978, 253, 4128-4136. 
18. Schlaepfer, I.R.; Rider, L.; Rodrigues, L.U.; Gijón, M.A.; Pac, C.T.; Romero, L.; Cimic, A.; Sirintrapun, S.J.; Glode, L.M.; Eckel, R.H.; et al. Lipid catabolism via CPT1 as a therapeutic target for prostate cancer. Mol. Cancer Ther. 2014, 13, 2361-2371. [CrossRef]

19. Flaig, T.W.; Salzmann-Sullivan, M.; Su, L.-J.; Zhang, Z.; Joshi, M.; Gijón, M.A.; Kim, J.; Arcaroli, J.J.; Van Bokhoven, A.; Lucia, M.S.; et al. Lipid catabolism inhibition sensitizes prostate cancer cells to antiandrogen blockade. Oncotarget 2017, 8, 56051-56065. [CrossRef]

20. Itkonen, H.M.; Brown, M.; Urbanucci, A.; Tredwell, G.; Lau, C.H.; Barfeld, S.; Hart, C.; Guldvik, I.J.; Takhar, M.; Heemers, H.V.; et al. Lipid degradation promotes prostate cancer cell survival. Oncotarget 2017, 8, 38264-38275. [CrossRef]

21. Samudio, I.; Harmancey, R.; Fiegl, M.; Kantarjian, H.; Konopleva, M.; Korchin, B.; Kaluarachchi, K.; Bornmann, W.; Duvvuri, S.; Taegtmeyer, H.; et al. Pharmacologic inhibition of fatty acid oxidation sensitizes human leukemia cells to apoptosis induction. J. Clin. Investig. 2010, 120, 142-156. [CrossRef] [PubMed]

22. Wang, Y.-N.; Zeng, Z.-L.; Lu, J.; Wang, Y.; Liu, Z.-X.; He, M.-M.; Zhao, Q.; Wang, Z.-X.; Li, T.; Lu, Y.-X.; et al. CPT1A-mediated fatty acid oxidation promotes colorectal cancer cell metastasis by inhibiting anoikis. Oncogene 2018, 37, 6025-6040. [CrossRef] [PubMed]

23. Park, J.H.; Vithayathil, S.; Kumar, S.; Sung, P.-L.; Dobrolecki, L.E.; Putluri, V.; Bhat, V.B.; Bhowmik, S.K.; Gupta, V.; Arora, K.; et al. Fatty Acid Oxidation-Driven Src Links Mitochondrial Energy Reprogramming and Regulation of Oncogenic Properties in Triple Negative Breast Cancer. Cell Rep. 2016, 14, 2154-2165. [CrossRef] [PubMed]

24. Schoors, S.; Bruning, U.; Missiaen, R.; Queiroz, K.C.; Borgers, G.; Elia, I.; Zecchin, A.; Cantelmo, A.R.; Christen, S.; Goveia, J.; et al. Fatty acid carbon is essential for dNTP synthesis in endothelial cells. Nature 2015, 520, 192-197. [CrossRef] [PubMed]

25. McDonnell, E.; Crown, S.B.; Fox, D.B.; Kitir, B.; Ilkayeva, O.R.; Olsen, C.A.; Grimsrud, P.A.; Hirschey, M.D. Lipids reprogram metabolism to become a major carbon source for histone acetylation. Cell Rep. 2016, 17, 1463-1472. [CrossRef] [PubMed]

26. Wong, B.W.; Wang, X.; Zecchin, A.; Thienpont, B.; Cornelissen, I.; Kalucka, J.; Garcia-Caballero, M.; Missiaen, R.; Huang, H.; Bruning, U.; et al. The role of fatty acid beta-oxidation in lymphangiogenesis. Nature 2017, 542, 49-54. [CrossRef] [PubMed]

27. Thalmann, G.N.; Anezinis, P.E.; Chang, S.M.; Zhau, H.E.; Kim, E.E.; Hopwood, V.L.; Pathak, S.; Von Eschenbach, A.C.; Chung, L.W.K. Androgen-independent cancer progression and bone metastasis in the LNCaP model of human prostate cancer. Cancer Res. 1994, 54, 2577-2581. [PubMed]

28. Wu, Z.; Conaway, M.; Gioeli, D.; Weber, M.; Theodorescu, D. Conditional expression of PTEN alters the androgen responsiveness of prostate cancer cells. Prostate 2006, 66, 1114-1123. [CrossRef]

29. Schlaepfer, I.R.; Glode, L.M.; Hitz, C.A.; Pac, C.T.; Boyle, K.E.; Maroni, P.; Deep, G.; Agarwal, R.; Lucia, S.M.; Cramer, S.D.; et al. Inhibition of Lipid Oxidation Increases Glucose Metabolism and Enhances 2-Deoxy-2-[18F]Fluoro-D-Glucose Uptake in Prostate Cancer Mouse Xenografts. Mol. Imaging Boil. 2015, 17, 529-538. [CrossRef]

30. Sramkoski, R.M.; Pretlow, T.G.; Giaconia, J.M.; Pretlow, T.P.; Schwartz, S.; Sy, M.-S.; Marengo, S.R.; Rhim, J.S.; Zhang, D.; Jacobberger, J.W. A new human prostate carcinoma cell line, 22Rv1. Vitr. Cell. Dev. Boil.-Anim. 1999, 35, 403-409. [CrossRef]

31. Toren, P.; Kim, S.; Johnson, F.; Zoubeidi, A. Combined AKT and MEK Pathway Blockade in Pre-Clinical Models of Enzalutamide-Resistant Prostate Cancer. PLoS ONE 2016, 11. [CrossRef] [PubMed]

32. Sedelaar, J.M.; Isaacs, J.T. Tissue Culture Media Supplemented with 10\% Fetal Calf Serum Contains a Castrate level of Testosterone. Prostate 2009, 69, 1724-1729. [CrossRef] [PubMed]

33. Kamphorst, J.J.; Chung, M.K.; Fan, J.; Rabinowitz, J.D. Quantitative analysis of acetyl-CoA production in hypoxic cancer cells reveals substantial contribution from acetate. Cancer Metab. 2014, 2. [CrossRef] [PubMed]

34. Lasko, L.M.; Jakob, C.G.; Edalji, R.P.; Qiu, W.; Montgomery, D.; Digiammarino, E.L.; Hansen, T.M.; Risi, R.M.; Frey, R.; Manaves, V.; et al. Discovery of a selective catalytic p300/CBP inhibitor that targets lineage-specific tumours. Nature 2017, 550. [CrossRef] [PubMed]

35. Han, W.; Gao, S.; Barrett, D.; Ahmed, M.; Han, D.; Macoska, J.A.; He, H.H.; Cai, C. Reactivation of androgen receptor-regulated lipid biosynthesis drives the progression of castration-resistant prostate cancer. Oncogene 2018, 37, 710-721. [CrossRef] [PubMed] 
36. Qu, Q.; Zeng, F.; Liu, X.; Wang, Q.J.; Deng, F. Fatty acid oxidation and carnitine palmitoyltransferase I: Emerging therapeutic targets in cancer. Cell Death Dis. 2016, 7. [CrossRef] [PubMed]

37. DeBerardinis, R.J.; Chandel, N.S. Fundamentals of cancer metabolism. Sci. Adv. 2016, 2. [CrossRef] [PubMed]

38. Pike, L.S.; Smift, A.L.; Croteau, N.J.; Ferrick, D.A.; Wu, M. Inhibition of fatty acid oxidation by etomoxir impairs NADPH production and increases reactive oxygen species resulting in ATP depletion and cell death in human glioblastoma cells. Biochim. Biophys. Acta 2011, 1807, 726-734. [CrossRef] [PubMed]

39. Watt, M.J.; Clark, A.K.; Selth, L.A.; Haynes, V.R.; Lister, N.; Rebello, R.; Porter, L.H.; Niranjan, B.; Whitby, S.T.; Lo, J.; et al. Suppressing fatty acid uptake has therapeutic effects in preclinical models of prostate cancer. Sci. Transl. Med. 2019, 11. [CrossRef] [PubMed]

40. Kuhajda, F.P.; Date, O.; Katsura, M.; Ishida, M.; Yoshihara, T.; Kinomura, A.; Sueda, T.; Miyagawa, K. Fatty Acid Synthase and Cancer: New Application of an Old Pathway: Figure 1. Cancer Res. 2006, 66, 5977-5980. [CrossRef]

41. Little, J.L.; Wheeler, F.B.; Fels, D.R.; Koumenis, C.; Kridel, S.J. Inhibition of Fatty Acid Synthase Induces Endoplasmic Reticulum Stress in Tumor Cells. Cancer Res. 2007, 67, 1262-1269. [CrossRef]

42. Migita, T.; Ruiz, S.; Fornari, A.; Fiorentino, M.; Priolo, C.; Zadra, G.; Inazuka, F.; Grisanzio, C.; Palescandolo, E.; Shin, E.; et al. Fatty Acid Synthase: A Metabolic Enzyme and Candidate Oncogene in Prostate Cancer. J. Natl. Cancer Inst. 2009, 101, 519-532. [CrossRef] [PubMed]

43. Dart, D.A.; Brooke, G.N.; Sita-Lumsden, A.; Waxman, J.; Bevan, C.L. Reducing prohibitin increases histone acetylation, and promotes androgen independence in prostate tumours by increasing androgen receptor activation by adrenal androgens. Oncogene 2012, 31, 4588-4598. [CrossRef] [PubMed]

44. Mostaghel, E.A.; Solomon, K.R.; Pelton, K.; Freeman, M.R.; Montgomery, R.B. Impact of Circulating Cholesterol Levels on Growth and Intratumoral Androgen Concentration of Prostate Tumors. PLoS ONE 2012, 7. [CrossRef] [PubMed]

45. Lam, H.-M.; Corey, E. Supraphysiological Testosterone Therapy as Treatment for Castration-Resistant Prostate Cancer. Front. Oncol. 2018, 8. [CrossRef]

46. Hubbert, C.; Guardiola, A.; Shao, R.; Kawaguchi, Y.; Ito, A.; Nixon, A.; Yoshida, M.; Wang, X.-F.; Yao, T.-P. HDAC6 is a microtubule-associated deacetylase. Nature 2002, 417, 455-458. [CrossRef]

47. Zhou, L.X.; Li, T.; Huang, Y.R.; Sha, J.J.; Sun, P.; Li, D. Application of histone modification in the risk prediction of the biochemical recurrence after radical prostatectomy. Asian J. Androl. 2010, 12, 171-179. [CrossRef] [PubMed]

48. Welsbie, D.S.; Xu, J.; Chen, Y.; Borsu, L.; Scher, H.I.; Rosen, N.; Sawyers, C.L. Histone deacetylases are required for androgen receptor function in hormone-sensitive and castrate-resistant prostate cancer. Cancer Res. 2009, 69, 958-966. [CrossRef]

49. Lee, J.-H.; Yang, B.; Lindahl, A.J.; Damaschke, N.; Boersma, M.D.; Huang, W.; Corey, E.; Jarrard, D.F.; Denu, J.M. Identifying Dysregulated Epigenetic Enzyme Activity in Castrate-Resistant Prostate Cancer Development. ACS Chem. Boil. 2017, 12, 2804-2814. [CrossRef]

50. Patsoukis, N.; Bardhan, K.; Chatterjee, P.; Sari, D.; Liu, B.; Bell, L.N.; Karoly, E.D.; Freeman, G.J.; Petkova, V.; Seth, P.; et al. PD-1 alters T-cell metabolic reprogramming by inhibiting glycolysis and promoting lipolysis and fatty acid oxidation. Nat. Commun. 2015, 6, 6692. [CrossRef]

51. Higano, C.S.; Armstrong, A.J.; Sartor, A.O.; Vogelzang, N.J.; Kantoff, P.W.; McLeod, D.G.; Pieczonka, C.M.; Penson, D.F.; Shore, N.D.; Vacirca, J.; et al. Real-world outcomes of sipuleucel-T treatment in PROCEED, a prospective registry of men with metastatic castration-resistant prostate cancer. Cancer 2019. [CrossRef] [PubMed]

(C) 2019 by the authors. Licensee MDPI, Basel, Switzerland. This article is an open access article distributed under the terms and conditions of the Creative Commons Attribution (CC BY) license (http://creativecommons.org/licenses/by/4.0/). 